\title{
ESPAÇO URBANO E SEGURANÇA PRIVADA: OS PODERES DOS SEGURANÇAS PRIVADOS DE OBSTRUIR ENTRADA/SAÍDA E EXPULSAR
}

\author{
Caio Cardoso de Moraes (Ciências Sociais- UEL) \\ E-mail: caiocardosodemoraes@gmail.com
}

\section{RESUMO}

Cada vez mais os espaços urbanos estão sendo vigiados por agentes de segurança privada. A partir do século XX, houve um aumento vertiginoso de espaços privados de massa, como shoppings centers, condomínios residenciais, boates, agências bancárias etc. Com essa mudança no espaço urbano, parte significativa da vida coletiva migrou para dentro desses espaços, cujo serviço de segurança é executado por agentes privados. Assim sendo, urge a necessidade de compreender quais as origens legais dos poderes dos seguranças particulares e os limites para o seu exercício. Esta pesquisa se debruça, especialmente, sobre os poderes e limites dos seguranças particulares de obstruir entradas e saídas e expulsar pessoas. Para tanto, foram analisados acórdãos judiciais que envolvem a mobilização de poderes de obstrução de entrada/saída e expulsão por agentes da segurança privada. Os documentos foram coletados no site do Tribunal de Justiça de São Paulo (TJ-SP) e do Tribunal de Justiça do Paraná (TJ-PR) e são referentes às decisões julgadas entre 2010 e 2012. Foram analisados por meio de análise quantitativa descritiva e análise de conteúdo. A análise mostra que o judiciário tem limitado a atuação dos seguranças mesmo existindo ferramentas legais que permitem o uso desses poderes.

Palavras-chave: Segurança privada; poderes legais; espaço privado de massa.

\section{INTRODUÇÃO}

O Brasil segue uma tendência global de transferência de responsabilidades de prover segurança do Estado para a sociedade (LOPES, 2013). O reflexo da pluralização dos agentes provedores de segurança pode ser notado no crescimento das atividades de policiamento executadas pelo setor de segurança privada. Segundo Lopes (2013), em 2011 havia no Brasil pelo menos um profissional de segurança privada para cada profissional de segurança pública.

Cada vez mais os espaços urbanos estão sendo policiados por seguranças particulares, consequentemente, cada vez mais os cidadãos estão sendo vigiados por agentes desse setor. Ao exercer a função de prover segurança, esses profissionais mobilizam uma série de poderes tais como: uso de força física, prisão, revista, obstrução de entrada/saída, expulsão. Esses poderes interferem nos direitos dos cidadãos e, portanto, se faz necessário compreender quais os fundamentos legais dos seguranças particulares para mobilizarem esses poderes bem como seus limites.

Este trabalho se debruça, especialmente sobre os poderes de obstrução de entrada/saída e expulsão. A fonte legal desses poderes provém, em grande medida, do direito da propriedade. Nesse contexto, é preciso levar em consideração as transformações que vêm ocorrendo no espaço urbano, ou seja, a partir do século XX 


\section{SEMINÁRIO DE PESQUISA EM CIÊNCIAS HUMANAS - SEPECH \\ Humanidades, Estado e desafios didático-científicos \\ Londrina, 27 a 29 de julho de 2016}

assistimos a um aumento vertiginoso de espaços privados aberto ao público ou "espaço privado de massa" tais como: shoppings center, bancos, condomínios residenciais, boates, clubes etc (BUTTON, 2007; STENNING, 2000; VON HIRSCH, SHEARING, 2000). Esses espaços, apesar de privados, exercem funções públicas, pois importantes bens sociais, serviços, emprego, compra e lazer ocorrem dentro deles. Portanto, a obstrução de acesso ou a exclusão exercida pelos agentes da segurança privada, mesmo que fundamentada no direito da propriedade, pode interferir em direitos individuais importantes (VON HIRSCH; SHEARING, 2000).

Em meio a poucas pesquisas acerca dessa temática no Brasil, este trabalho pretende contribuir com a lacuna na bibliografia, especialmente sobre os poderes dos seguranças particulares de obstruir entradas/saídas e expulsar pessoas. Quais as origens legais do poder dos seguranças particulares em obstruir entradas/saídas e expulsar pessoas? Qual o fundamento desses poderes? Quais os limites impostos ao exercício desses poderes? São essas as questões que o trabalho pretende responder.

\section{OS PODERES DA SEGURANÇA PRIVADA: O DEBATE NA BIBLIOGRAFIA ACADÊMICA}

Com o aumento vertiginoso do setor de segurança privada, cada vez mais as pessoas estão sendo policiadas por agentes desse setor. No entanto, não está muito claro, nem para a bibliografia acadêmica e nem para a sociedade civil, quais os poderes legais desses agentes e os limites desses poderes. Ao exercer sua função, esses profissionais podem interferir em direitos individuais dos cidadãos quando obstruem entradas/saída, expulsam, usam força física ou efetuam prisões.

Para Stenning (2000), os agentes de segurança privada contam com uma "caixa de ferramentas" para exercer sua função de prover segurança. Esse conjunto de ferramentas é formado por ferramentas físicas e tecnológicas como armas letais e não letais, algemas, rádio para comunicação, automóveis etc; ferramentas pessoais como treinamentos, habilidades linguísticas, força física etc; e as ferramentas simbólicas como uniformes, status, respeito etc. Essas ferramentas estão disponíveis aos agentes particulares de segurança e podem ser mobilizados quando necessário para o exercício de sua função.

As ferramentas legais também são importantes e compõem o conjunto de ferramentas disponíveis ao profissional provedor de segurança (BUTTON, 2007; STENNING, 2000). Para Button (2007), os poderes legais dos seguranças privados provêm de duas fontes: 1) ferramentas legais universais; 2) ferramentas legais seletivas. As ferramentas legais universais referem-se aos direitos disponíveis a qualquer cidadão, como o direito de usar força física em determinadas circunstância, dentro do limite da razoabilidade e da proporcionalidade, por exemplo, na prevenção de crimes ou na detenção de criminosos suspeitos. As ferramentas legais seletivas estão baseadas em outras fontes legais como contratos de trabalho ou direito à propriedade. Essas ferramentas estão disponíveis apenas para agentes que atuam em situações específica e garantem a eles, alguns poderes específicos que nem mesmo a polícia tem à disposição, tais como o poder de obstrução de entrada/saída e expulsão. 


\section{SEMINÁRIO DE PESQUISA EM CIÊNCIAS HUMANAS - SEPECH \\ Humanidades, Estado e desafios didático-científicos \\ Londrina, 27 a 29 de julho de 2016}

\section{AS TRANSFORMAÇÕES NO ESPAÇO URBANO E A SEGURANÇA PRIVADA}

O espaço público vem sendo entendido como um espaço de liberdade onde as pessoas têm o direito de ir e vir, desde que não viole os regulamentos de conduta gerais, como alguma lei. Esses espaços estão disponíveis a qualquer cidadão e não requer autorização específica. Os espaços privados são lugares em que os proprietários podem colocar limites sobre quem pode ou não usufruir esses espaços. Esses espaços oferecem outro tipo de liberdade: a do proprietário escolher quem pode entrar ou não em sua propriedade. (VON HIRSCH; SHEARING, 2000; SHEARING; WOOD, 2003).

A partir do século XX, surgem novas formas de espaços coletivos que a bibliografia especializada vem chamando de espaços privados de massa ou espaços privados abertos ao público tais como: shopping centers, condomínios residenciais, bancos, clubes, boates etc (VON HIRSCH; SHEARING, 2000; SHEARING; WOOD, 2003; SHEARING, 2000; BUTTON, 2007). Essas novas formas de espaços coletivos esbarram na distinção público/privado. São públicos no sentido de que são lugares comuns da vida cotidiana; e privados pois são propriedades privadas.

Com o desenvolvimento das propriedades privadas de massa, bens sociais importantes começaram a migrar para esses espaços. A exclusão - importante para assegurar a liberdade do proprietário - quando utilizada nesses novos espaços, acaba por restringir a liberdade de circulação e o acesso a bens sociais, serviços, compras, lazer e empregos. Para Von Hirsch e Shearing (2000), é importante reconhecer esses espaços privados como funcionalmente públicos e, portanto, repensar as complicações éticas e normativas que envolvem a exclusão de pessoas a esses espaços, sendo necessário pensar para além da distinção público/privado.

$\mathrm{Na}$ ausência de reflexões normativas sólidas para esses casos, quem regulamenta os poderes e limites das obstruções e exclusões é o Judiciário, portanto, é importante compreender o comportamento dos magistrados referente a esses casos, bem como os argumentos que fundamentam e limitam esses poderes.

\section{MATERIAL E MÉTODOS}

Esta pesquisa utiliza o banco de dados do projeto de pesquisa "Os Poderes da Segurança Privada" (UEL, n 08566), coordenado pelo prof. Dr. Cléber da Silva Lopes. O banco de dados é composto por 292 decisões judiciais de segunda instância (acórdãos), proferidas entre 2010 e 2012, no Tribunal de Justiça de São Paulo (TJ-SP) e no Tribunal de Justiça do Paraná (TJ-PR), envolvendo seguranças privados. Os documentos foram coletados nos sites dos respectivos tribunais.

Dos 292 acordãos, 155 envolvem obstrução de entrada/saída e expulsão, que é o foco deste trabalho. Os documentos foram analisados quantitativamente por meio de análise quantitativa descritiva exploratória e qualitativamente por meio de análise de conteúdo com auxílio de software. O intuito foi de identificar o argumento das decisões dos magistrados que legitimam e limitam os poderes de obstruir entrada/saída e expulsar dos seguranças privados. 


\section{SEMINÁRIO DE PESQUISA EM CIÊNCIAS HUMANAS - SEPECH \\ Humanidades, Estado e desafios didático-científicos \\ Londrina, 27 a 29 de julho de 2016}

\section{AS DECISÕES JUDICIAIS DO TJSP E TJPR ENVOLVENDO OBSTRUÇÃO DE ENTRADA/SAÍDA E EXPULSÃO FEITAS POR SEGURANÇAS PARTICULARES}

A amostra aleatória analisada neste trabalho é formada por 83 casos envolvendo obstrução de entrada, 44 envolvendo obstrução de saída e, 28 envolvendo expulsão, totalizando 155 casos. Dos casos que envolvem obstrução de entrada $88 \%$ ocorrem em agências bancárias. Dos casos envolvendo obstrução de saída $75 \%$ ocorrem em estabelecimento comerciais, enquanto que dos casos envolvendo expulsões $57 \%$ ocorrem em bares, restaurantes, clubes recreativos e casas noturnas. Esses dados indicam que as situações enfrentadas pelos seguranças no exercício de sua função são condicionadas pelos lugares em que atuam, e, portanto, demandam determinadas atitudes. Para compreender as especificidades dos fundamentos e dos limites de cada poder, eles serão analisados separadamente.

Dos 83 casos envolvendo obstrução de entrada, 46\% $(n=38)$ geraram condenação em segunda instância. Apesar da maioria dos casos não ter gerado condenação, a porcentagem que gerou ainda é bastante expressiva. $\mathrm{O}$ quadro a seguir busca demonstrar o conteúdo dos principais argumentos dos magistrados que legitimam o poder de obstrução de entrada.

\begin{tabular}{|c|c|c|}
\hline & & Trecho \\
\hline \multirow{5}{*}{ Fundamentos } & $\begin{array}{lr}\text { Conflito } & \text { de } \\
\text { direito } & \text { e } \\
\text { prevalência } & \text { da } \\
\text { segurança } & \end{array}$ & $\begin{array}{l}\text { Trata-se, pois, de claro embate de direitos fundamentais. } \\
\text { De um lado, o direito à segurança dos correntistas e, de } \\
\text { outro, o direito do recorrente de adentrar na sua agência } \\
\text { bancária para retirada de valores e, no caso concreto, o } \\
\text { direito fundamental da coletividade deve ceder espaço } \\
\text { em detrimento da entrada imediata do autor nas } \\
\text { dependências do banco. (P228: 20120000011348) }\end{array}$ \\
\hline & $\begin{array}{l}\text { Direito de se } \\
\text { proteger }\end{array}$ & $\begin{array}{l}\text { Não se nega o direito das Instituições Financeiras em } \\
\text { instalar portas de segurança em suas agências, [...] por } \\
\text { exigência da violência urbana e em prol da segurança } \\
\text { dos clientes, funcionários e do seu patrimônio. (P316: } \\
\text { 20120000262590) }\end{array}$ \\
\hline & $\begin{array}{l}\text { Legítima } \\
\text { defesa }\end{array}$ & - \\
\hline & $\begin{array}{l}\text { Exercício } \\
\text { regular } \\
\text { direito }\end{array}$ & $\begin{array}{l}\text { Em época de extrema violência para a segurança de } \\
\text { todos os cidadãos, não se discute que o Banco age no } \\
\text { exercício regular de direito quando veda o acesso ao } \\
\text { interior das agências bancárias de pessoas que tragam } \\
\text { consigo material de metal. (P157: 0003400682) }\end{array}$ \\
\hline & $\begin{array}{l}\text { Fundada } \\
\text { suspeita } \\
\text { legítima }\end{array}$ & $\begin{array}{l}\text { O ingresso de pessoas nas agências bancárias é livre e só } \\
\text { deve } \\
\text { ser impedido em casos de suspeitas fundadas de risco à } \\
\text { integridade dos clientes ou ao patrimônio do Banco, } \\
\text { sendo normalmente utilizadas portas de segurança que } \\
\text { travam automaticamente quando identificada a presença } \\
\text { de elementos metálicos (que se presume serem armas). }\end{array}$ \\
\hline
\end{tabular}




\section{SEMINÁRIO DE PESQUISA EM CIÊNCIAS HUMANAS - SEPECH \\ Humanidades, Estado e desafios didático-científicos \\ Londrina, 27 a 29 de julho de 2016}

\begin{tabular}{|c|c|c|}
\hline & & (P115: 0003348797) \\
\hline & $\begin{array}{ll}\text { Dever } & \text { de } \\
\text { prover } & \\
\text { segurança } & \end{array}$ & $\begin{array}{l}\text { A finalidade da porta com detectores de metais é } \\
\text { impedir atentados violentos contra as agências } \\
\text { bancárias, assim, se esta é ativada pela presença de certa } \\
\text { quantidade de metal (a suficiente para caracterizar uma } \\
\text { arma), é dever dos prepostos do Banco obstar o ingresso } \\
\text { das pessoas que sejam barradas pelo dispositivo. (P366: } \\
\text { 03715745) }\end{array}$ \\
\hline \multirow{4}{*}{$\begin{array}{l}\text { Dispositivos } \\
\text { jurídicos }\end{array}$} & Constituição & 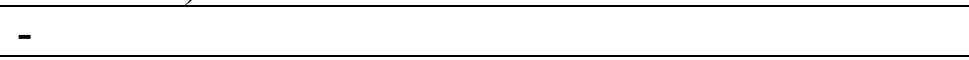 \\
\hline & Lei e Decreto & $\begin{array}{l}\text { (...) indiscutível a necessidade das instituições bancárias } \\
\text { adotarem medidas de segurança, garantindo a sua } \\
\text { tranquila utilização do serviço. Até mesmo porque } \\
\text { respondem objetivamente a atos lesivos ocorridos dentro } \\
\text { do estabelecimento, nos termos da Lei } \mathbf{n}^{\circ} \mathbf{7 . 1 0 2 / 8 3} \text {. (...) } \\
\text { (P107: 0003541436) }\end{array}$ \\
\hline & Jurisprudência & $\begin{array}{l}\text { A jurisprudência tem entendido no sentido de se } \\
\text { reconhecer a licitude da instalação de porta detectora de } \\
\text { metais em agências bancárias, como medida de proteção } \\
\text { dos funcionários e usuários, tendo em vista os elevados } \\
\text { índices de insegurança pública, caracterizando a ação } \\
\text { mero exercício regular de direito. }\end{array}$ \\
\hline & Doutrina & $\begin{array}{l}\text { Aliás, ensina YUSSEF SAID CAHALI que "Em } \\
\text { princípio, assim, não haveria responsabilidade civil por } \\
\text { danos morais em favor do cliente barrado na porta } \\
\text { giratória do banco, em caso de ausência de prova de que } \\
\text { o segurança da instituição bancária tenha agido de forma } \\
\text { abusiva, ou mesmo com excessos, ao buscar a } \\
\text { averiguação dos pertences do autor, a fim de liberar a } \\
\text { sua entrada no estabelecimento" in Dano Moral, RT, } 4^{\mathrm{a}} \\
\text { ed./2011, p. } 471 \text {. }\end{array}$ \\
\hline
\end{tabular}

Quadro 1 - Fundamentos e Dispositivos jurídicos que legitimam o poder de obstrução de entrada ${ }^{1}$

Fonte: TJ-SP e TJ-PR.

A Lei $\mathrm{n}^{\circ} 7.102 / 83$ responsabiliza as agências bancárias pelos atos lesivos ocorridos dentro de seus estabelecimentos, impondo a elas o dever de prover segurança. Dessa maneira, parece bastante claro para o ordenamento jurídico e para a jurisprudência, o poder dos seguranças privados de obstruir entradas em agências bancárias.

Se existem fundamentos e dispositivos jurídicos claros sobre o poder de obstrução de entrada, quais as situações e argumentos que limitam tal poder? O quadro

\footnotetext{
${ }^{1}$ Todos os trechos selecionados para compor o quadro referem-se às decisões judiciais que envolvem obstrução de entrada em agências bancárias, pois a maioria dos casos de obstrução de entrada ocorrem nesses locais, portanto, a maioria dos argumentos também se referem a essas situações.
} 


\section{SEMINÁRIO DE PESQUISA EM CIÊNCIAS HUMANAS - SEPECH \\ Humanidades, Estado e desafios didático-científicos \\ Londrina, 27 a 29 de julho de 2016}

a seguir mostra os principais fundamentos e dispositivos jurídicos utilizados pelos magistrados para caracterizar abuso do poder de obstruir entradas.

\begin{tabular}{|c|c|c|}
\hline & & Trecho \\
\hline \multirow[t]{3}{*}{ Fundamentos } & $\begin{array}{l}\text { Ofensa } \\
\text { imagem }\end{array}$ & $\begin{array}{l}\text { Todavia, as medidas adotadas pelos prepostos da } \\
\text { instituição financeira, em especial a proibição do ingresso } \\
\text { do Autor após esclarecer que o metal que a máquina } \\
\text { estava detectando era o da parte interna da sua bota, } \\
\text { configuraram excesso e causaram embaraços, percalços e } \\
\text { desconforto ao Apelado que extrapolaram o } \\
\text { constrangimento natural decorrente do travamento da } \\
\text { porta detectora de metal, ensejando o reconhecimento do } \\
\text { dano moral de pequena monta. (P357: 0003688089) }\end{array}$ \\
\hline & $\begin{array}{l}\text { Ofensa à } \\
\text { integridade } \\
\text { física e à vida }\end{array}$ & $\begin{array}{l}\text { Diante desse quadro, não há dúvida de que o empregado } \\
\text { da ré, de forma injusta e gratuita, agrediu fisicamente o } \\
\text { autor, causando-lhe constrangimento e humilhação. } \\
\text { (P206: 20110000146167) }\end{array}$ \\
\hline & $\begin{array}{lr}\text { Ofensa } & \text { à } \\
\text { liberdade } & \text { de } \\
\text { locomoção } & \end{array}$ & - \\
\hline \multirow{4}{*}{$\begin{array}{l}\text { Dispositivos } \\
\text { jurídicos }\end{array}$} & Constituição & - \\
\hline & Lei e Decreto & $\begin{array}{l}\text { Assim, conclui-se que os atos praticados pelos prepostos } \\
\text { da agência contra a autora ofenderam indevidamente, } \\
\text { seus sentimentos, provocando constrangimento, tristeza, } \\
\text { mágoa e atribulações na esfera interna pertinente à } \\
\text { sensibilidade moral, gerando o dever de indenizar, nos } \\
\text { termos do art. } 186 \text { do Código Civil. (P270: } \\
20120000108767)\end{array}$ \\
\hline & Jurisprudência & $\begin{array}{l}\text { Tem entendido a jurisprudência que a presença das portas } \\
\text { ou o travamento pelo cliente portar telefone celular ou } \\
\text { metais em certa quantidade, por si só não caracteriza o } \\
\text { constrangimento, que, porém, poderá decorrer: "dos } \\
\text { desdobramentos que lhe possam suceder, assim } \\
\text { consideradas as iniciativas que a instituição bancária ou } \\
\text { seus prepostos venham a tomar no momento, as quais } \\
\text { poderão minorar os efeitos da ocorrência, fazendo com } \\
\text { que ela assuma contornos de uma mera contrariedade, ou, } \\
\text { de outro modo, agravá-los, degenerando o que poderia ser } \\
\text { um simples contratempo em fonte de vergonha e } \\
\text { humilhação, passíveis, estes sim, de reparação" (P316: } \\
\text { 20120000262590) }\end{array}$ \\
\hline & Doutrina & - \\
\hline
\end{tabular}

Quadro 2 - Fundamentos e Dispositivos jurídicos sobre o abuso do poder de obstrução de entrada

Fonte: TJ-SP e TJ-PR. 


\section{SEMINÁRIO DE PESQUISA EM CIÊNCIAS HUMANAS - SEPECH \\ Humanidades, Estado e desafios didático-científicos \\ Londrina, 27 a 29 de julho de 2016}

Os principais casos que os magistrados caracterizam como abuso do poder de obstruir entradas, especialmente em agências bancárias, referem-se à indivíduos com botas com biqueiras de metal ou indivíduos portadores de prótese metálicas, barrados pelas portas giratórias detectoras de metais. Essas situações também parecem bastante claras para os magistrados e para a jurisprudência. $\mathrm{O}$ abuso, portanto, não advém do travamento da porta em si, mas sim, dos desdobramentos de tal, ou seja, das ações dos seguranças particulares após o travamento da porta. Outros casos caracterizados como abuso do poder de obstruir entradas que não ocorrem em agências bancárias também seguem o mesmo raciocínio, ou seja, o abuso não é configurado pela obstrução em si, mas pela forma como é executada. Portanto, sobre os poderes dos seguranças particulares obstruírem entradas, está bastante claro para o judiciário que é um poder legítimo e que o abuso desse poder é caracterizado pela forma como é efetuado, ou seja, a obstrução de entrada legítima não deve constranger o indivíduo.

Sobre os casos envolvendo obstrução de saída, $75 \% \quad(n=33)$ geraram condenação, o que sugere que é um tipo de ação que vem sendo bastante limitada pelo judiciário. O quadro a seguir seleciona os principais fundamentos e dispositivos jurídicos que legitimam esse tipo de ação pelos seguranças privados.

\begin{tabular}{|c|c|c|}
\hline & & Trecho \\
\hline \multirow{5}{*}{ Fundamentos } & $\begin{array}{lr}\text { Conflito de } \\
\text { direito } \\
\text { prevalência } \\
\text { segurança }\end{array}$ & - \\
\hline & $\begin{array}{l}\text { Direito de se } \\
\text { proteger }\end{array}$ & $\begin{array}{l}\text { Ante tal quadro, a funcionária e os seguranças da } \\
\text { recorrida agiram para proteger o patrimônio desta, } \\
\text { dentro da normalidade, sem abuso ou excesso, sem a } \\
\text { prática de qualquer ofensa, não tendo eles exposto a } \\
\text { recorrente a constrangimento ou humilhação perante } \\
\text { outras pessoas, o que afasta a possibilidade de } \\
\text { acolhimento da pretensão de indenização por danos } \\
\text { morais (...) (P246: 20120000412897) }\end{array}$ \\
\hline & $\begin{array}{l}\text { Legítima } \\
\text { defesa }\end{array}$ & - \\
\hline & $\begin{array}{l}\text { Exercício } \\
\text { regular } \\
\text { direito }\end{array}$ & $\begin{array}{l}\text { Em relação ao invocado exercício regular de direito, é } \\
\text { inegável que constitui prerrogativa aceitável a } \\
\text { interceptação de clientes que sejam suspeitos da prática } \\
\text { de conduta ilícita no interior do estabelecimento. } \\
\text { Contudo, este direito deve ser exercido no âmbito da } \\
\text { razoabilidade, devendo os prepostos guardar a mais } \\
\text { estrita urbanidade, respeito e discrição, sem expor o } \\
\text { cliente perante terceiros, agindo a vigilância de forma } \\
\text { discreta e sem maiores exposições, com o escopo de não } \\
\text { sujeitá-lo a situação vexatória e humilhante em público. } \\
\text { (P32: 695087600) }\end{array}$ \\
\hline & $\begin{array}{l}\text { Fundada } \\
\text { suspeita } \\
\text { legítima } \\
\end{array}$ & $\begin{array}{l}\text { Ora, havendo a suspeita por parte do Supermercado, } \\
\text { tem-se o direito de averiguar o fato. E, sendo feita a } \\
\text { abordagem de forma discreta, sem causar tumultos e }\end{array}$ \\
\hline
\end{tabular}




\section{SEMINÁRIO DE PESQUISA EM CIÊNCIAS HUMANAS - SEPECH \\ Humanidades, Estado e desafios didático-científicos \\ Londrina, 27 a 29 de julho de 2016}

\begin{tabular}{|c|c|c|}
\hline & & $\begin{array}{l}\text { constrangimento, não há que se falar no dever de } \\
\text { indenizar. (P36: 732066900) } \\
\text { Sendo assim, a revista realizada na bolsa da apelante, in } \\
\text { casu, por prepostos da recorrida, ante a suspeita de ter a } \\
\text { primeira praticado furto de mercadoria no âmbito do } \\
\text { supermercado, constitui instrumento legítimo de } \\
\text { proteção ao patrimônio. (P246: 20120000412897) }\end{array}$ \\
\hline & $\begin{array}{ll}\text { Dever } & \text { de } \\
\text { prover } & \\
\text { segurança } & \end{array}$ & $\begin{array}{l}\text { Portanto, as pessoas envolvidas com o fato ocorrido } \\
\text { agiram nos limites de suas funções, diante do dever de } \\
\text { oferecer segurança aos frequentadores do } \\
\text { estacionamento, sem qualquer prova, repita-se, das } \\
\text { agressões imputadas a um dos seguranças. (P252: } \\
\text { 20120000577429) }\end{array}$ \\
\hline \multirow{4}{*}{$\begin{array}{l}\text { Dispositivos } \\
\text { jurídicos }\end{array}$} & Constituição & - \\
\hline & Lei e Decreto & - \\
\hline & Jurisprudência & $\begin{array}{l}\text { Nesse sentido, segue entendimento jurisprudencial: } \\
\text { "Dano moral. Alarme falso. Ausência de tratamento } \\
\text { abusivo pelo segurança da loja como destacado no } \\
\text { acórdão. 1. Se soa o alarme e não há indicação de que } \\
\text { houve tratamento abusivo de nenhum empregado da } \\
\text { loja, no caso, o segurança, sequer objeto da queixa da } \\
\text { autora, não se pode identificar a existência de } \\
\text { constrangimento suficiente a deferir o dano moral. Para } \\
\text { que a indenização por dano moral seja procedente é } \\
\text { necessário que haja alguma atitude que exponha o } \\
\text { consumidor a uma situação de humilhação, de } \\
\text { constrangimento, que o acórdão, neste feito, descartou } \\
\text { por inteiro. 2. Recurso especial conhecido e desprovido" } \\
\text { (Resp n. 658.975-RS, Relator Ministro Carlos Alberto } \\
\text { Menezes Direito, julgado em } 29 \text { de novembro de 2006). } \\
\text { (P277: 20120000193482) }\end{array}$ \\
\hline & Doutrina & - \\
\hline
\end{tabular}

Quadro 3 - Fundamentos e Dispositivos jurídicos que legitimam o poder de obstrução de saída

Fonte: TJ-SP e TJ-PR.

O conteúdo das decisões judiciais mostra que o poder de obstrução de saída é permitido basicamente mediante fundada suspeita legítima, ou seja, quando o indivíduo é flagrado cometendo um delito ou furto. Com exceção da jurisprudência, os outros dispositivos jurídicos não são mobilizados pelos magistrados nesse tipo de situação, o que sugere a ausência de dispositivos jurídicos que legitimam a obstrução de saída pelos seguranças privados. Assim, o poder dos seguranças privados de obstruir saídas se mostra bastante restrito. O quadro a seguir seleciona os fundamentos e dispositivos jurídicos mobilizados pelos magistrados para configurar o abuso do poder de obstruir saídas. 


\begin{tabular}{|c|c|c|}
\hline & & Trecho \\
\hline \multirow[t]{3}{*}{ Fundamentos } & $\begin{array}{l}\text { Ofensa } \\
\text { imagem }\end{array}$ & $\begin{array}{l}\text { (...) a conduta da ré afetou diretamente tais valores [a } \\
\text { vida e a moral do ser humano, dentre outro, atributos } \\
\text { inerentes à dignidade da pessoa humana] quando, } \\
\text { assemelhando-se a práticas comuns na idade-média ou } \\
\text { típicas de regimes ditatoriais - no que diz respeito a } \\
\text { condução dos malfeitores aos calabouços e porões - } \\
\text { levou o consumidor para a dita "salinha", permitindo } \\
\text { toda sorte de abusos verbais e físicos não monitorados, a } \\
\text { fim de obter o ressarcimento de seus prejuízos. É } \\
\text { humilhante submeter o consumidor a tal prática, } \\
\text { independentemente da efetiva ocorrência ou não de } \\
\text { furto, ainda mais se tratando de mera suspeita em } \\
\text { relação à subtração de um produto. (P74: } 780176700 \text { ) } \\
\text { Evidente que a Requerida podia exercer o direito de } \\
\text { vigilância no estabelecimento comercial, o que, porém, } \\
\text { não possibilitava que seus prepostos fizessem a } \\
\text { abordagem do Autor na presença de vários clientes que } \\
\text { puderam acompanhar os fatos (seis seguranças } \\
\text { impediram o Autor de deixar o local e revistaram a sua } \\
\text { sacola). Caracterizado o dano à personalidade do Autor } \\
\text { em razão da ilícita conduta dos prepostos da Requerida } \\
\text { e das circunstâncias fáticas (suspeita da prática de furto, } \\
\text { e abordagem constrangedora na presença de vários } \\
\text { clientes), daí a condenação ao pagamento da } \\
\text { indenização. (P269: } 20120000084141 \text { ) }\end{array}$ \\
\hline & $\begin{array}{l}\text { Ofensa à } \\
\text { integridade } \\
\text { física e à vida }\end{array}$ & $\begin{array}{l}\text { (...) os prepostos do réu não poderiam nunca chegar ao } \\
\text { extremo a que chegaram, aos atos de violência } \\
\text { constatado por um dos policiais militares chamados ao } \\
\text { local por outro cliente do hipermercado: com o seu rosto } \\
\text { sendo esfregado no chão. Deveriam os seguranças, na } \\
\text { medida do necessário para a solução do problema, pedir } \\
\text { ao autor a devolução da caixa de cerveja ou, em caso de } \\
\text { recusa, diante da suspeita de furto ou de outra } \\
\text { irregularidade, obstar a sua saída do prédio e chamar de } \\
\text { imediato a Polícia; nunca, sob o pretexto da legítima } \\
\text { defesa da propriedade, dominá-lo, levá-lo a uma sala } \\
\text { separada, mantê-lo ali cativo por algum tempo sem } \\
\text { esfregar o seu rosto no chão. Houve um excesso, o que } \\
\text { desfigura a legítima defesa, que requer moderação no } \\
\text { emprego dos meios. (P82: } 717769900 \text { ) }\end{array}$ \\
\hline & $\begin{array}{l}\text { Ofensa } \\
\text { liberdade } \\
\text { locomoção }\end{array}$ & $\begin{array}{l}\text { (...) a detenção foi ilegal, uma vez que não se tratava de } \\
\text { situação de flagrante delito, sequer havendo indícios da } \\
\text { prática de crime, configurando, pois, evidente abuso por } \\
\text { parte dos prepostos da ré envolvidos nos fatos, que se } \\
\text { excederam na prática de suas funções, causando } \\
\text { evidente constrangimento aos autores, apontados }\end{array}$ \\
\hline
\end{tabular}




\section{SEMINÁRIO DE PESQUISA EM CIÊNCIAS HUMANAS - SEPECH \\ Humanidades, Estado e desafios didático-científicos \\ Londrina, 27 a 29 de julho de 2016}

\begin{tabular}{|c|c|c|}
\hline & & $\begin{array}{l}\text { injustamente como delinqüentes e cerceados em seu } \\
\text { direito de ir e vir. (P220: 20110000285928) }\end{array}$ \\
\hline \multirow{4}{*}{$\begin{array}{l}\text { Dispositivos } \\
\text { jurídicos }\end{array}$} & Constituição & - \\
\hline & Lei e Decreto & $\begin{array}{l}\text { por se tratar de relação de consumo, o ônus de } \\
\text { comprovar que agiu diligentemente, sem lesar outrem, } \\
\text { era do fornecedor, máxime a responsabilidade objetiva } \\
\text { encetada no artigo } 14 \text { do CDC: Art. 14. O fornecedor } \\
\text { de serviços responde, independentemente da existência } \\
\text { de culpa, pela reparação dos danos causados aos } \\
\text { consumidores por defeitos relativos à prestação dos } \\
\text { serviços, bem como por informações insuficientes ou } \\
\text { inadequadas sobre sua fruição e riscos. (P74: } \\
780176700 \text { ) }\end{array}$ \\
\hline & Jurisprudência & $\begin{array}{l}\text { Ademais, referente ao tema posto em debate, o E. } \\
\text { Tribunal de Justiça de São Paulo vem assim decidindo: } \\
\text { "Apelação cível. Indenizatória por danos morais. } \\
\text { Alarme antifurto, disparado em porta de supermercado. } \\
\text { Sentença de procedência. Apelo da ré. Prova } \\
\text { testemunhal confirmatória da tese esposada pelos } \\
\text { autores. Caixa registrador que não retirou o dispositivo } \\
\text { de alarme. Constrangimento dos autores apelados, } \\
\text { agravado pela revista pessoal das mercadorias } \\
\text { adquiridas, em local de ampla movimentação de pessoas } \\
\text { (porta de entrada do estabelecimento). Orientação da } 4^{\text {a }} \\
\text { Turma do C. Superior Tribunal de Justiça. Dano moral } \\
\text { configurado. (P276: 20120000148954) }\end{array}$ \\
\hline & Doutrina & $\begin{array}{l}\text { Yussef Said Cahali afirma, por exemplo, que "vem } \\
\text { sendo reiteradamente decidido que configura dano } \\
\text { moral reparável o constrangimento a que é submetido o } \\
\text { freguês do estabelecimento comercial, ao ser compelido } \\
\text { a sujeitar-se a revista pelo serviço de segurança da } \\
\text { empresa sob suspeita de subtração de mercadorias, sem } \\
\text { que venha a ser demonstrada a prática de furto pelo } \\
\text { mesmo" ("Dano Moral", } 3^{\text {a }} \text { ed., RT, p. 575). (P14: } \\
\text { 20110000282354) }\end{array}$ \\
\hline
\end{tabular}

Quadro 4 - Fundamentos e Dispositivos jurídicos sobre o abuso do poder de obstrução de saída

Fonte: TJ-SP e TJ-PR.

Se a fundada suspeita é o fundamento que legitima a obstrução de saída, o Quadro 4 revela que a infundada suspeita é o fundamento gerador de danos morais e condenação. O artigo 14 do Código de Defesa do Consumidor, amplamente citado para embasar o abuso da obstrução de saída, responsabiliza o fornecedor de serviços, independentemente da existência de culpa, pela reparação dos danos causados aos consumidores por defeitos relativos à prestação de seus serviços. O quadro também revela que os magistrados levam em conta a forma da abordagem dos seguranças particulares ao obstar saídas para caracterizar o abuso. A análise dos acórdãos mostra que não está claro para o judiciário a forma correta da abordagem, pois quando feita na 


\section{SEMINÁRIO DE PESQUISA EM CIÊNCIAS HUMANAS - SEPECH \\ Humanidades, Estado e desafios didático-científicos \\ Londrina, 27 a 29 de julho de 2016}

frente de outras pessoas, geram danos morais e constrangimento e, quando feitas em salas separadas, também. Dessa forma, o poder de obstrução de saída pelos seguranças privados é bastante limitado, não existindo dispositivos jurídicos que legitimam essa ação, porém, os magistrados utilizam dispositivos jurídicos para caracterizar o abuso.

Quanto aos casos envolvendo expulsão feitas por seguranças privados, 57\% $(n=16)$ dos casos analisados geraram condenação. A expulsão geralmente é executada para revogar a autorização de acesso mediante comportamento não esperado. No entanto, nenhum dispositivo jurídico foi mobilizado pelos magistrados para legitimar o poder de expulsar dos seguranças privados. A fundada suspeita foi o único fundamento mobilizado para legitimar a ação, sendo o comportamento não esperado o principal fator que justifica a expulsão. A ausência de fundamentos e dispositivos jurídicos que legitimam o poder de expulsar dos seguranças particulares revela os limites da utilização desse poder pelos seguranças particulares. $O$ quadro a seguir seleciona os principais fundamentos e dispositivos jurídicos mobilizados pelos magistrados para caracterizar o abuso do poder de expulsar dos seguranças privados.

\begin{tabular}{|c|c|c|}
\hline & & \begin{tabular}{|l|} 
Trecho \\
\end{tabular} \\
\hline \multirow{3}{*}{ Fundamentos } & $\begin{array}{l}\text { Ofensa } \\
\text { imagem }\end{array}$ & $\begin{array}{l}\text { Pelo que se depreende dos autos, a conduta dos } \\
\text { seguranças tomou proporções inaceitáveis ao iniciar } \\
\text { com a abordagem do autor no caixa, condução do } \\
\text { mesmo ao interior da boate e, posterior retirada do local } \\
\text { de forma grosseira, além do uso de palavras ofensivas à } \\
\text { honra e a imagem do autor. (P298: 0003273828) }\end{array}$ \\
\hline & $\begin{array}{l}\text { Ofensa à } \\
\text { integridade } \\
\text { física e à vida }\end{array}$ & $\begin{array}{l}\text { A lesão injustificada à integridade física, praticada em } \\
\text { público por quem tinha o dever de zelar pela } \\
\text { incolumidade física dos presentes, coloca a vítima em } \\
\text { situação humilhante. A ofensa à honra é inegável e deve } \\
\text { ser indenizada. (P133: 0002911965) }\end{array}$ \\
\hline & $\begin{array}{l}\text { Ofensa } \\
\text { liberdade } \\
\text { locomoção }\end{array}$ & $\begin{array}{l}\text { De qualquer modo, o equívoco não se justifica, porque } \\
\text { representou verdadeiro cerceamento da liberdade do } \\
\text { usuário, que foi tratado como se criminoso fosse, por } \\
\text { pura presunção e falta de cautela dos funcionários. } \\
\text { (P362: } 0003777722 \text { ) }\end{array}$ \\
\hline $\begin{array}{l}\text { Dispositivos } \\
\text { jurídicos }\end{array}$ & Constituição & $\begin{array}{l}\text { Da análise dos autos, de fato, se conclui que a prova } \\
\text { testemunhal e documental acostada aos autos comprova, } \\
\text { com a necessária segurança, a ocorrência da referida } \\
\text { agressão verbal, de conteúdo preconceituoso. É } \\
\text { importante ressaltar que a matéria em discussão tem } \\
\text { abrangência constitucional, vez que um dos objetivos } \\
\text { fundamentais da República Federativa do Brasil é } \\
\text { "promover o bem de todos, sem preconceitos de origem, } \\
\text { raça, sexo, cor, idade e quaisquer outras formas de } \\
\text { discriminação" (artigo } 3^{\circ} \text {, IV, CF). Não existe } \\
\text { justificativa para a prática de discriminação, de modo } \\
\text { que toda e qualquer conduta que seja considerada } \\
\text { preconceituosa deve ser repelida. Ora, o legislador } \\
\text { constituinte assegurou, indistintamente, o direito à vida }\end{array}$ \\
\hline
\end{tabular}




\section{SEMINÁRIO DE PESQUISA EM CIÊNCIAS HUMANAS - SEPECH \\ Humanidades, Estado e desafios didático-científicos \\ Londrina, 27 a 29 de julho de 2016}

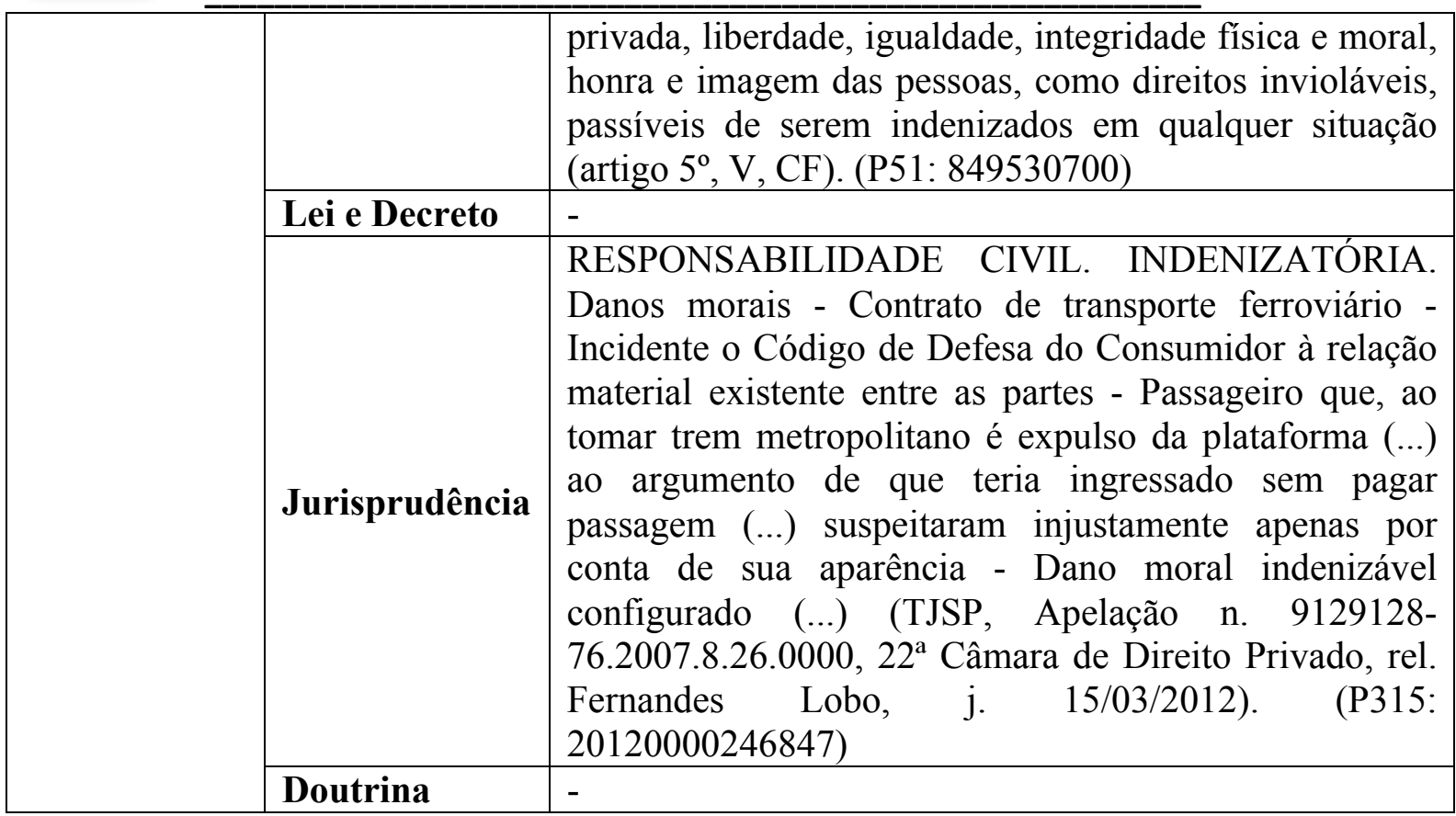

Quadro 5 - Fundamentos e Dispositivos jurídicos sobre o abuso do poder de expulsão Fonte: TJ-SP e TJ-PR.

Ao executar a expulsão, muitas vezes o segurança privado necessita fazer uso da força física. $\mathrm{O}$ quadro mostra que o abuso não é caracterizado pela expulsão em si, mas pela forma como ela é executada, especialmente pelo uso desproporcional de força física e por agressões verbais. Ainda, com exceção das jurisprudências, nenhum dispositivo jurídico que trata estritamente do poder e limites dos seguranças privados de expulsar pessoas foi mobilizado. Fato que mostra que os poderes e limites dos seguranças privados de expulsar ainda são bastante obscuros para o judiciário.

\section{CONCLUSÃO}

A análise empírica dos 155 acórdãos envolvendo obstrução de entrada/saída e expulsão executadas por seguranças privados confirma algumas hipóteses levantadas pela bibliografia. Para Button (2007), os poderes da segurança privada advêm, em grande medida, de outras fontes legais como direito à propriedade e contratos de trabalho. Nos casos analisados foi confirmado essa hipótese especialmente sobre o poder dos seguranças privados de obstruir entradas em agências bancárias. Esse poder advém, em grande medida, da Lei $\mathrm{n}^{\circ} 7.102 / 83$ que obriga os bancos a tomarem medidas de segurança, como é o caso das portas detectoras de metais. Entretanto, sobre os poderes dos seguranças particulares de obstruir saídas e expulsar, nenhuma lei ou decreto foi mobilizado para legitimar esses poderes. Ademais, entre os três poderes analisados, o que gerou menos condenação e, consequentemente aparece como o mais legítimo para o judiciário, é exatamente a obstrução de entrada em agências bancárias que têm uma lei como fonte de poder para as ações dos seguranças privados.

Se para Button (2007) a fonte de poder dos seguranças privados advém de outras fontes legais, a análise empírica aqui empreendida revela que os limites dos poderes também advêm de outras fontes. É o caso da obstrução de saída, que nos casos 


\section{SEMINÁRIO DE PESQUISA EM CIÊNCIAS HUMANAS - SEPECH \\ Humanidades, Estado e desafios didático-científicos \\ Londrina, 27 a 29 de julho de 2016}

analisados não foi mobilizado nenhum dispositivo jurídico, com exceção da jurisprudência, para legitimar esse poder dos seguranças privados, no entanto, o artigo 14 do Código de Defesa do Consumidor foi amplamente citado para embasar o abuso da obstrução de saída e responsabilizar os prestadores de serviços pelos danos morais causados aos consumidores. Não por acaso, é o poder que mais gerou condenação entre os três analisados. Já sobre os casos envolvendo expulsão, a análise mostra que os dispositivos jurídicos, com exceção das jurisprudências, também não são mobilizados, nem como fonte de poder, nem como limite, o que revela que os poderes e limites dos seguranças privados de expulsar ainda são bastante obscuros para o judiciário.

A análise empírica sobre os poderes e limites dos seguranças privados de obstruir entradas/saídas e expulsar mostra que, tanto os poderes, quanto os limites, dependem da existência e da clareza dos dispositivos jurídicos que envolvem esses poderes, ou seja, a Lei $n^{\circ} 7.102 / 83$ que serve como fonte do poder de obstruir entradas em agências bancárias e o artigo 14 do Código de Defesa do Consumidor que serve como fonte de limite do poder de obstruir saídas. Dos 155 casos analisados, $56 \%(\mathrm{n}=87)$ geraram condenação, o que mostra que, independente das fontes legais que legitimam a atuação dos seguranças privados, o judiciário vem limitando bastante os seus poderes.

\section{REFERÊNCIAS BIBLIOGRÁFICAS}

BAUER, M. Análise de Conteúdo Clássica: Uma Revisão. In: BAUER, M. \& GASKELL, G. Pesquisa Qualitativa com Texto, Imagem e Som: um manual prático. $2^{\circ}$ ed. Petrópolis/RJ: Vozes, 2002.

BUTTON, Mark. Security Officers and Policing: Powers, Culture and Control in the Governance of Private Space. Ashgate Publishing Limited, 2007.

GIBBS, G. Codificação e Categorização Temáticas. In ibid. Análise de Dados Qualitativos. Porto Alegre: Artmed, 2009.

KELLE, U. Análise com Auxílio de Computador: codificação e indexação. In: BAUER, M. \& GASKELL, G. Pesquisa Qualitativa com Texto, Imagem e Som: um manual prático. $2^{\circ}$ ed. Petrópolis/RJ: Vozes, 2002.

LOPES, C.S. Os poderes da segurança privada: um estudo exploratório sobre a atuação dos profissionais regulares de segurança privada nas cidades de São Paulo e Londrina. Projeto de Pesquisa n 08566, Universidade Estadual de Londrina, 2013.

SHEARING, C. D.; WOOD, J. Nodal Governance, Democracy and the New 'Denizens'. Journal of Law and Society. Vol. 30, No. 3, p. 400-419, 2003.

STENNING, P.C. Powers and Accountability of Private Police. European Journal on Criminal Policy Research, v.8, n.3, p. 325-352, 2000. 
VON HIRSCH, A. SHEARING, C. Exclusion from Public Space. In VON HIRSCH, A.; GARLAND, D. and WAKEFIELD, A. (eds). Ethical and social perspectives on situational crime prevention. Oxford and Portland: Hart Publising, 2000. 